\title{
Medication adherence and its determinants amongst anti-hypertensive patients in a tertiary care hospital in Navi Mumbai
}

\author{
Satyendra B. Badhe ${ }^{1 *}$, Pramila V. Yadav ${ }^{2}$, Pradnya S. Deolekar², \\ Suvarna B. Badhe ${ }^{1}$, Mihika Aggarwal ${ }^{1}$
}

\author{
${ }^{1}$ D.Y. Patil University, School of Medicine, Nerul, Navi Mumbai, Maharashtra, India \\ ${ }^{2}$ Department of Pharmacology, D.Y. Patil University, School of Medicine, Nerul, Navi Mumbai, Maharashtra, India
}

Received: 05 November 2019

Revised: 14 December 2019

Accepted: 16 December 2019

\section{*Correspondence:}

Dr. Satyendra B. Badhe,

Email: satyendrabbadhe@gmail.com

Copyright: (C) the author(s), publisher and licensee Medip Academy. This is an open-access article distributed under the terms of the Creative Commons Attribution Non-Commercial License, which permits unrestricted non-commercial use, distribution, and reproduction in any medium, provided the original work is properly cited.

\begin{abstract}
Background: Anti-hypertensive drugs can effectively control hypertension, subject to good adherence. Uncontrolled hypertension can lead to numerous complications, some even potentially fatal, such as myocardial infarction, atherosclerosis, thromboembolism, shock and stroke.

Methods: A cross-sectional prospective study was conducted with the help of a pre-validated questionnaire during the course of 6 months in the medicine outpatient department and the inpatient department (wards) at a tertiary care hospital, Navi Mumbai in 200 hypertensive patients to calculate the correlation of the sociodemographic factors with adherence by the chi-squared test.

Results: The overall percentage of adherence to antihypertensive medication was $34.8 \%$. It was the highest $(72.1 \%)$ in the younger age group, i.e., below 50 years. It was observed that as the age increases, the adherence to treatment decreases. Adherence rates were significantly higher among females and those individuals who had never attended school. Among the employed, $70.3 \%$ were adherent to their treatment and among the unemployed, $64.4 \%$ were adherent. The percentage of adherence was lower in alcohol consumers $(9.5 \%)$ as compared to nonusers (76\% and $32 \%$, respectively).

Conclusions: The clinician advising anti-hypertensive therapy should provide thorough counselling and stress on the issues created due to poor medication adherence as hypertension can be associated with severe outcomes. Treatments should be given in accordance with each patient's lifestyles in mind such that they may continue taking their medications till the completion of their therapy.
\end{abstract}

Keywords: Anti-hypertensive drugs, Adherence, Sociodemographic factors

\section{INTRODUCTION}

According to the $8^{\text {th }}$ revision of the Joint National Committee (JNC) guidelines, hypertension can be defined as a condition wherein the arterial blood pressure values of a patient are consistently raised above $140 \mathrm{~mm}$ of mercury (systolic) and $90 \mathrm{~mm}$ of mercury (diastolic). ${ }^{1}$ It is the most dangerous non-communicable disease known to mankind, potentially causing heart attacks and strokes which are among the most common causes of death in the world today. As many as 400-500,000 premature deaths in India could be prevented by better hypertension control. ${ }^{2}$ Anti-hypertensive drugs can effectively control hypertension, subject to good adherence. Uncontrolled hypertension can lead to numerous complications, some even potentially fatal, 
such as myocardial infarction, atherosclerosis, thromboembolism, shock and stroke.

Adherence is defined by the World Health Organization as "the degree to which the person's behavior corresponds with the agreed recommendations from a health care provider." 3 It takes into account the lifestyle, needs and preferences of a patient with regards to ongoing medical treatment. A drug given to a patient for a pre-existing pathology can only prove effective as a means of treatment when it is administered with regularity and appropriate frequency. Inconsistencies in consuming tablets or pills leads to non-adherence of the drug. Subsequently, unproductive management of the disorder and a worsening prognosis can result. Hence, studying the adherence of hypertensive patients towards anti-hypertensive drugs can help develop the treatment and quality of life for these patients in the future.

The importance of adherence is further underlined upon observing the fact that hypertension a disorder which can be well controlled simply with regular anti-hypertensive medications. Certain personally variable factors such as age, sex, employment, alcoholism and so on have been postulated to contribute to non-adherence to medical treatment. This study aims to determine the correlation between these sociodemographic factors and medication adherence for hypertensive patients in our locality, Navi Mumbai.

\section{METHODS}

After taking approval from the Institutional Ethics Committee, a cross-sectional prospective study was conducted during the course of 6 months (August 2018 January 2019) in the medicine outpatient department and the in-patient department (wards) at DY Patil Hospital and Research Center, Navi Mumbai. The sample size was calculated as in accordance with the required proportion of a confidence level of $95 \%$, a margin of error was $5 \%$ and a proportion of compliance was 0.73 used in a previous study, 200 was the sample size calculated for data collection. ${ }^{4}$

The inclusion Criteria were 200 clinically diagnosed hypertensive (as per the guidelines put forth by the $8^{\text {th }}$ revision of the JNC in 2014) patients, diagnosed since at least one year, with or without any coexisting pathologies and between the ages of 35-85 years were asked for their informed written consent to participate in this quantitative study. ${ }^{1}$ Patients with conditions like dementia, pregnant state or any incapacitating/fatal prognosis were excluded from the study.

\section{Statistical analysis}

These patients answered a questionnaire which was tested and used in a similar previous study by Shah et al 2018 , from which data was collected. ${ }^{5}$ In this Likert- 5 questionnaire, numerical values were allotted for differing grades of adherence for each patient. The various socio-demographic factors implicated in the etiology of hypertension were asked for each patient. Through these values, the incidence rate of hypertension was determined. In this study, the relationship between various socio-demographic factors and hypertension was correlated via the Pearson's correlation co-efficient 'p'. A value of $p<0.05$ was considered significant. Using these values, a chi-squared test was conducted for each factor affecting hypertension to establish the relationship between the two. The duration of study was 6 months.

Each patient's adherence to their treatment was observed by the healthy changes made in their lifestyles and by adhering to their individual medication schedules. Nonadherence to antihypertensive therapy is defined as skipping even one prescribed dose daily for $>3$ days in a week, lifestyle habits such as smoking, consumption of alcohol $>2$ standard drinks for men and 1 standard drink for women, table salt of $>1$ teaspoon $(2400 \mathrm{mg}$ ) per day over and above normal use and meat consumption frequently ( $\geq 3$ days in the week).

The data collected was analyzed using percentages and proportions. Chi-square test was applied, wherein $\mathrm{p} \leq 0.05$ was considered statistically significant.

\section{RESULTS}

Out of the total study population of 200 individuals interviewed, 109 were females $(54.5 \%)$ and 91 were males $(45.5 \%)$. The mean for age of all the participants was calculated to be $62.2 \pm 14.6$ years (with the range of age being 18 to 65 years). The percentage of adherence to antihypertensive medication calculated was $34.8 \%$.

The proportion of adherence in the younger age group, i.e., below 50 years was the highest $(72.1 \%)$. It was observed that as the age increases, the adherence to treatment decreases. Adherence rates were significantly higher among females and those individuals who had never attended school. Among the employed, $70.3 \%$ of all the individuals were adherent to their treatment, and among the unemployed, $64.4 \%$ were adherent. The percentage of adherence was lower among smokers $(2.5 \%)$ but was not found to be statistically significant. The percentage of adherence was lower in alcohol consumers $(9.5 \%)$ as compared to nonusers $(76 \%$ and $32 \%$, respectively) (Table 1 ).

The questionnaire also had reasons for non-adherence. The main reasons reported by participants for frequently skipping medication were, $44 \%$ forgetting to take medication, while $31.1 \%$ discontinued the medication when feeling well, and $11.6 \%$ skipped the medication due to the expenses incurred on it.

About $76.6 \%$ of the participants engaged in physical exercise daily or frequently. $58 \%$ of the participants frequently had table salt. The current study shows that $12 \%$ of the total participants were smokers and $15.5 \%$ were consuming alcohol. 
Table 1: Association between sociodemographic factors and adherence.

\begin{tabular}{|c|c|c|c|c|}
\hline \multirow{2}{*}{ Variables } & Adherent & Non-adherent & Total & Significance \\
\hline & $\mathrm{N}(\%)$ & $\mathrm{N}(\%)$ & & \\
\hline \multicolumn{5}{|l|}{ Age (yrs) } \\
\hline $35-45$ & $27(13.5)$ & $8(4)$ & 35 & NS \\
\hline $45-55$ & $29(14.5)$ & $21(10.5)$ & 50 & \\
\hline$>55$ & $13(6.5)$ & $102(51)$ & 115 & \\
\hline \multicolumn{5}{|l|}{ Sex } \\
\hline Male & $54(27)$ & $37(18.5)$ & 91 & $\mathrm{~S}$ \\
\hline Female & $76(38)$ & $33(16.5)$ & 109 & \\
\hline \multicolumn{5}{|l|}{ Education } \\
\hline Illiterate & 87 (43.5) & $25(12.5)$ & 104 & NS \\
\hline Primary school & $16(8)$ & $9(4.5)$ & 25 & \\
\hline Secondary and higher & $59(29.5)$ & $12(6)$ & 71 & \\
\hline \multicolumn{5}{|l|}{ Marital status } \\
\hline Married & $93(46.5)$ & $78(39)$ & 171 & $\mathrm{~S}$ \\
\hline Not married & $17(8.5)$ & $12(6)$ & 29 & \\
\hline \multicolumn{5}{|l|}{ Employment status } \\
\hline Employed & $106(53)$ & $60(30)$ & 166 & $\mathrm{~S}$ \\
\hline Unemployed & $19(9.5)$ & $15(7.5)$ & 34 & \\
\hline \multicolumn{5}{|l|}{ Smoking } \\
\hline Yes & $5(2.5)$ & $21(10.5)$ & 24 & NS \\
\hline No & $152(76)$ & $24(12)$ & 176 & \\
\hline \multicolumn{5}{|l|}{ Alcohol intake } \\
\hline Yes & $19(9.5)$ & $12(6)$ & 31 & $\mathrm{~S}$ \\
\hline No & $64(32)$ & $105(52.5)$ & 169 & \\
\hline
\end{tabular}

NS: Non significance; S: Significance.

\section{DISCUSSION}

In this study, the proportion of individuals who were nonadherent to antihypertensive treatment was $65.5 \%$. In a similar study done in Mangalore and Pakistan, it was $45.8 \%$ and $51.7 \%$, respectively. ${ }^{6,7}$ Our study showed a higher rate of non-adherence as compared to other studies. This may be due to a difference in the sociodemographic profile of the study area.

Females were found to be significantly more compliant than males. A study in Vietnam also showed that adherence was low among males. ${ }^{8}$ This may be due to the side effects of antihypertensive medication, (mainly thiazide diuretics and beta-blockers except nebivolol) such as impotence, affecting particularly males, as shown in meta-analysis. ${ }^{9}$

Decreased proportion of adherence with antihypertensive medication among smokers and those who consumed alcohol was consistent with the findings of a study conducted in Mangalore. ${ }^{6}$ The proportion of treatment compliance $(72.1 \%)$ was better in the younger age group, i.e., below 50 years. It was observed that as age increases, compliance to treatment decreases. This is similar to a study conducted in Tanzania. ${ }^{10}$ Younger individuals are usually employed, and thus, they can afford to buy their medication regularly. In this study, forgetfulness was found to be a predominant reason for skipping medication. Elderly participants are likely to forget their dose as compared to younger participants.

Adherence was significantly more among those who never went to school, i.e., $82.7 \%$ than those who received school education $(64.6 \%)$. This is consistent with a study done on factors affecting compliance in Tanzania and England who found that patients without formal education had better compliance to medication. ${ }^{10,11}$ This may be because patients with lower educational level might have more trust in the physicians' advice.

The clinician advising anti-hypertensive treatment should place firm emphasis on the issues associated with poor adherence to the prescribed medication as hypertension can be associated with severe outcomes. It has been associated with the inability to achieve BP control and a significant increase in the risk for all-cause mortality and hospitalization due to cardiovascular events. ${ }^{12}$ Therefore, depending on each patient's case, clinicians should work closely with patients and select the appropriate regimen and time of administration in order to improve adherence.

The limitation of this study was that it involved a subjective method, based on the patient's answers, to assess compliance. Further studies can be done using an objective assessment such as using blister packs that electronically record the opening of compartments. Little 
attention has been paid to patients' perceived understanding of their illness and medication. Insight into their perception rather than the expectations and perception of the healthcare professionals may have relevance for understanding noncompliance to medication in a better manner. ${ }^{5}$

\section{CONCLUSION}

On processing the collected data, the adherence to antihypertensive medication was found to be poor, amounting to $34.8 \%$ of the total study population. The results also provided an insight into non-adherence. Forgetfulness, the presence of addictions (alcohol and smoking) and a subjective feeling of well-being before the completion of medical therapy were some of the most common causes given for non-adherence to antihypertensive medication. Appropriate lifestyle modifications should be encouraged as they have been associated with better medication adherence which aids the ability to achieve BP control and can help prevent the significant risk of complications due to hypertension.

Funding: No funding sources

Conflict of interest: None declared

Ethical approval: The study was approved by the Institutional Ethics Committee

\section{REFERENCES}

1. James PA, Oparil S, Carter BL, Cushman WC, Dennison-Himmelfarb C, Handler J, et al. 2014 Evidence-Based Guideline for the Management of High Blood Pressure in Adults Report From the Panel Members Appointed to the Eighth Joint National Committee (JNC 8). JAMA. 2014;311(5):507-20.

2. Rajeev G, Xavier D. Hypertension: The Most Important Non-Communicable Disease Risk Factor in India. Egyptian Journal of Medical Human Genetics, Elsevier; 2018. Available at: www.sciencedirect.com/science/article/pii/S0019483 21730593X. Accessed on 31 October 2019.

3. Dobbels F, Van Damme-Lombaert R, Vanhaecke J, De Geest S. Growing pains: non-adherence with the immunosuppressive regimen in adolescent transplant recipients. Pediatr Transplant. 2005;9(3):381-90.

4. Bhandari S, Sarma PS, Thankappan KR. Adherence to antihypertensive treatment and its determinants among urban slum dwellers in Kolkata, India. Asia Pac J Public Health. 2015;27:74-84.

5. Shah AJ, Singh V, Patil SP, Gadkari MR, Ramchandani V, Doshi KJ. Factors affecting compliance to antihypertensive treatment among adults in a tertiary care hospital in Mumbai. Indian $\mathbf{J}$ Community Med. 2018;43:53-5

6. Kumar N, Unnikrishnan B, Thapar R, Mithra P, Kulkarni V, Holla R, et al. Factors associated with adherence to antihypertensive treatment among patients attending a tertiary care hospital in Mangalore, South India. IJCRR. 2014;6:77-85.

7. Ahmed N, Abdul Khaliq M, Shah SH, Anwar W. Compliance to antihypertensive drugs, salt restriction, exercise and control of systemic hypertension in hypertensive patients at Abbottabad. J Ayub Med Coll Abbottabad. 2008;20:66-9.

8. Nguyen TP, Schuiling Veninga CC, Nguyen TB, Vu TH, Wright EP, Postma MJ, et al. Adherence to hypertension medication: Quantitative and qualitative investigations in a rural Northern Vietnamese community. PLoS One. 2017;12:e0171203.

9. Baumhäkel M, Schlimmer N, Kratz M, Hackett G, Jackson G, Böhm M, et al. Cardiovascular risk, drugs and erectile function - A systematic analysis. Int $\mathbf{J}$ Clin Pract. 2011;65:289-98.

10. Joho AA. Factors Affecting Treatment Compliance among Hypertension Patients in Three District Hospitals - Dar es Salaam. Masters Thesis, Muhimbili University of Health and Allied Sciences; 2012. Available at: http://www.ihi.eprints.org/1584. Accessed on 31 October 2019.

11. Senior V, Marteau TM, Weinman J. Genetic Risk Assessment for FH Trial (GRAFT) Study Group. Self reported adherence to cholesterol lowering medication in patients with familial hypercholesterolaemia: The role of illness perceptions. Cardiovasc Drugs Ther. 2004;18:475-81.

12. Grassi G, Seravalle G, Mancia G. Cardiovascular consequences of poor compliance to antihypertensive therapy. Blood Press. 2011;20(4):196-203.

Cite this article as: Badhe SB, Yadav PV, Deolekar PS, Badhe SB, Aggarwal M. Medication adherence and its determinants amongst antihypertensive patients in a tertiary care hospital in Navi Mumbai Int J Basic Clin Pharmacol 2020;9:328-31. 